\title{
Contando uma História do Movimento da Matemática Moderna em Jequié: memórias de dois professores
}

Naiane Nogueira Borges Souza

Januária Araújo Bertani

\section{Resumo}

Este artigo tem como objetivo analisar algumas formas de apropriação das recomendações do Movimento da Matemática Moderna de dois professores de Matemática que atuaram no curso secundário no período de 1960 a 1970 em Jequié-BA. Nesta pesquisa, como aporte teórico e metodológico, utilizamos a História Oral em que as narrativas trouxeram as memórias desses professores sobre as propostas de mudanças curriculares e metodológicas que ocasionaram no período um profundo impacto, causando resistência nos professores do curso secundário de Jequié, pois tanto os novos conteúdos que seriam inseridos no currículo, quanto as metodologias de ensino, seriam grandes desafios para as práticas docentes. Para atender essa demanda, esses professores participaram de cursos que foram promovidos pela Campanha de Aperfeiçoamento e Difusão do Ensino Secundário (CADES), tendo o intuito de se adaptarem àsnovas recomendações para o ensino de Matemática.

Palavras-Chave: História da Educação Matemática. Movimento da Matemática Moderna. Bahia. Jequié. 


\title{
Counting a Story of the Movement of Modern Mathematics in Jequié: memories of two teachers
}

\author{
Naiane Nogueira Borges Souza \\ Januária Araújo Bertani
}

\section{Abstract}

This article aims to analyze some appropriation ways of the recommendations of the Modern Mathematics Movement of two secondary course Mathematics teachers who worked from 1960 to 1970 in Jequié, Bahia, Brazil. In this research, we used Oral History, as theoretical and methodological contribution, in which the narratives brought the memories of these teachers on the proposals of curricular and methodological changes that caused a profound impact in that period, causing resistance in the secondary school teachers of Jequié, since both the new contents that would be inserted in the curriculum, and the teaching methodologies, would be great challenges for the teaching practices. To meet this demand, these teachers participated in courses that were promoted by the Campaign for Improvement and Diffusion of Secondary Education (Campanha de Aperfeiçoamento e Difusão do Ensino Secundário - CADES), aiming to adapt the new recommendations for mathematics teaching.

Keywords: History of Mathematics Education. Movement of Modern Mathematics. Bahia. Jequié. 


\section{Introdução}

Observamos que o Movimento da Matemática Moderna - MMM, apropriado pelos professores e difundido por meio de congressos e cursos, gerou alterações significativas no exercício da docência do curso secundário. Todavia, as pesquisas direcionadas à história das práticas docentes na disciplina de matemática em Jequié são poucas. Devido ao vasto campo nesta área, o nosso objetivo é investigar e compreender como ocorreu o processo de apropriação de dois professores sobre o MMM, bem como analisar os meios de apropriaçãa ${ }^{77}$ (cursos, palestras, livros e grupos de estudos, dentre outros) para a implementação da proposta defendida.

Para entender esse movimento, em Jequié, município do interior do estado da Bahia, recorremos à oralidade de dois professores de Matemática que atuavam no curso secundário no período de 1960 a 1970 a respeito das distintas versões sobre o MMM. Dessa forma, para a realização desta pesquisa utilizamos a metodologia de História Oral (HO) que nos permite “[...] (re)constituir algumas de suas várias versões, aos olhos de atores sociais que vivenciaram certos contextos e situações, considerando como elementos essenciais, nesse processo, as memórias desses atores [...]" (GARNICA, 2005, p. 6). A escolha pelo tema da pesquisa e pela metodologia está associada diretamente à experimentação da pesquisadora em um trabalho desenvolvido com HO na disciplina de História da Matemática no curso de Licenciatura em Matemática com Enfoque em Informática na Universidade Estadual do Sudoeste da Bahia.

\section{O Movimento da Matemática Moderna no Brasil}

Durante o período de 1955-1966 aconteceu uma série de cinco encontros para discutir sobre o ensino de Matemática no Brasil, nos quais se reuniram professores de Matemática de todas as regiões do país e, posteriormente, ocorreu a participação em âmbito internacional. O I Congresso foi realizado em Salvador (BA), em setembro de 1955, com a finalidade de analisar as circunstâncias existentes e delinear novos rumos para o Ensino da Matemática. O evento restringiu suas discussões em torno de assuntos como currículo do ensino básico, o livro do curso secundário, as novas tendências metodológicas de ensino, além do aprimoramento dos docentes (I CONGRESSO NACIONAL DO ENSINO DE MATEMÁTICA, 1957).

\footnotetext{
$77 \mathrm{O}$ conceito de apropriação, segundo Chartier (2001, p.67), "permite vincular as duas dimensões etimológicas que estão presentes nele: apropriar-se é estabelecer a propriedade sobre algo; e, desta maneira, o conceito de apropriação foi utilizado por Michel Foucault para descrever todos os dispositivos que tentam controlar a difusão e circulação dos discursos, estabelecendo a propriedade de alguns sobre o discurso por meio de suas formas materiais. E existe a apropriação no sentido da hermenêutica, que consiste no que os indivíduos fazem com o que recebem, e que é uma forma de invenção, de criação e de produção desde o momento em que se apoderam dos textos ou dos objetos recebidos. Desta maneira, o conceito de apropriação pode misturar o controle e a invenção, pode articular a imposição de um sentido e a produção de novos sentidos".
} 
Nesse congresso, em nenhum momento o termo "Matemática Moderna” foi abordado. No entanto, diversos estudos apresentados por educadores e pesquisadores presentes apontavam como deveria ser o ensino de matemática e a sua finalidade no ensino básico, demonstrando em seus registros um completo descontentamento com a proposta pedagógica aplicada nas escolas, além de convidar os professores atuantes da educação secundária a repensarem sobre o processo de ensino e aprendizagem. Como foi apresentado na tese defendida por Eleonora Lôbo Ribeiro:

\begin{abstract}
Urge, portanto, que os educadores se libertem da preocupação exagerada e, por vezes, a única de que estão possuídos, pelo conteúdo da matéria, tendo como objetivo, apenas, habilitar o aluno nas demonstrações dos teoremas, sem explorar algo mais elevado, sem fazer com que o aluno 'viva' o ensino; isto resulta em desilusão e descrédito do adolescente por não assimilar os conhecimentos ministrados e fracassar na vida prática, o que é uma consequência do caráter formal imprimido à Matemática (I CONGRESSO NACIONAL DO ENSINO DE MATEMÁTICA, 1957, p.52).
\end{abstract}

O II Congresso Nacional de Ensino da Matemática é identificado como lugar das primeiras discussões acerca do MMM. O encontro ocorreu no ano de 1957, em Porto Alegre (RS). Enquanto que oprimeiro congresso restringiu-se apenas ao ensino secundário, no segundoas discussões giraram em torno, também, do ensino primário e daformação do professor. O Congresso propôs estudos sobre a aprendizagem da Matemática nos diversos níveis de ensino e a influência da Matemática nas demais disciplinas.

No III Congresso, ocorrido em 1959, no Rio de Janeiro, os professores apresentaram teses sugerindo mudanças no processo formativo dos futuros docentes nas Faculdades de Filosofia e um aperfeiçoamento de professores através de cursos promovidos por estas faculdades. Nos anais desse encontro foi destacado como conclusão que:

Seja solicitado, aos Departamentos de Matemática das Faculdades de Filosofia de todo o país, a criação de cursos de preparação à Matemática Moderna, tais como Teoria dos Números, Lógica Matemática, Teoria dos Conjuntos, e Álgebra Moderna, para professores de Ensino Médio (III CONGRESSO NACIONAL DO ENSINO DA MATEMÁTICA, 1957, p. 213).

Após o III Congresso, vários espaços de discussão para a formação de professores foram constituídos no Brasil; dentre eles, o Centro de Ensino de Ciências da Bahia (CECIBA), em 1965. O CECIBA foi criado pelo Ministério da Educação e Cultura, em parceria com universidades e secretarias de educação, com a finalidade de "aperfeiçoar" o ensino de Matemática nas escolas (FREIRE, 2010). Para o ensino de Matemática foi constituída uma 
equipe de professores que era coordenada pela professora Martha Maria de Souza Dantas ${ }^{78}$. O CECIBA participou divulgando na Bahia a Matemática Moderna (MM) e promovendo cursos de aprimoramento para os professores recém-formados e para os que atuavam no ensino secundário. Esses cursos tinham o objetivo de modernizar os conhecimentos matemáticos já existentes dos docentes e discutir o ingresso da MM no currículo e na prática de ensino no curso secundário (DIAS, 2011).

Ainda de acordo com esse autor, não só na Bahia, mas em diversos outros estados do país, existia um grande número de professores que necessitava participar dos cursos de aperfeiçoamento para o ensino atualizado que propagavam no período. Entretanto, a Faculdade de Filosofia, onde eram realizados tais cursos, não conseguia atender a maioria dos professores do interior; portanto, ocorreu a iniciativa da criação da Campanha de Aperfeiçoamento e Difusão do Ensino Secundário (CADES). Esses cursos eram ministrados pelos docentes pertencentes à equipe do setor de Matemática do CECIBA, em sua maioria, docentes da Faculdade de Filosofia da Bahia.

A equipe do setor de Matemática do CECIBA elaborou o projeto de atualização do ensino de Matemática do curso secundário: Desenvolvimento de um Currículo para o Ensino atualizado da Matemática. Esse projeto foi desenvolvido no Colégio de Aplicação da UFBA79, com a finalidade de inserir a Matemática Moderna no ensino secundário da Bahia (LEME DA SILVA; CAMARGO, 2008). A equipe do setor de Matemática do CECIBA foi responsável por estruturar a coleção de livros didáticos "Matemática Moderna", os quais foram planejados com o intuito de experimentar um programa para o ensino de uma Matemática que aproximava a matemática das universidades, com a ensinada aos estudantes da escola secundária (SANTOS, 2012).

Caminhando nessa perspectiva, ocorreu o IV Congresso Nacional de Ensino da Matemática, em 1962, em Belém (PA). Soares (2005) o descreveu como sendo o congresso mais significativo para o MMM, sublinhando que um dos pontos de pauta era a 'Introdução da Matemática Moderna na Escola Secundária’. Nesse sentido, para o autor, o congresso abordou o assunto de maneira mais objetiva, expressando um novo olhar para uma vertente que havia sido conjecturada nos congressos anteriores. Fortalecendo essas ideias para o ensino primário e secundário ocorreu o V Congresso Nacional de Ensino da Matemática, em 1966, em São José dos Campos (SP), cujo temário foi "Matemática Moderna na escola secundária, articulações com o ensino primário e com o ensino secundário".

\footnotetext{
${ }^{78}$ Docente da Faculdade de Filosofia da Bahia na disciplina de Didática Especial da Matemática em períodos de 1952 a 1965. Foi uma das protagonistas do Movimento da Matemática Moderna no Brasil. O I Congresso Nacional do Ensino da Matemática, em 1955, foi organizado por Martha Dantas. Martha tinha um grande envolvimento com o ensino secundário de matemática na Bahia (Escola de Aplicação e CECIBA) (BERTANI, 2012).

79 Lando (2012), Rios (2016)
} 
Para conheceresse movimento internacional e sua difusão nacional, e, em particular no interior da Bahia, especificamente no município de Jequié, apresentaremos a seguir a apropriação do Movimento da Matemática Moderna de dois professores da época.

\section{Uma história da Matemática moderna em jequié: um olhar de dois professores da época}

Ao iniciar esta discussão faz-se necessário salientar que o intuito desta pesquisa não é contar a história da apropriação do MMM em Jequié, mas analisar uma das histórias dessa apropriação. Para isso, temos como fontes orais as narrativas de dois professores que atuaram no ensino da matemática nas décadas de 1960 e 1970.

A fim de encontrar as pessoas que participariam da nossa pesquisa, fomos a uma das escolas mais antigasde Jequié, o Instituto Estadual Régis Pacheco, em outubro de 2013. Lá obtivemos vários nomes e selecionamos esses dois contatos que, quando telefonamos, prontamente se dispuseram a falar sobre suas memórias. A expectativa e a ansiedade para conhecê-los e saber como seríamos recebidos eram grandes. Marcar o dia e horário que estariamdisponíveis para nos receber e estar presentesna data combinada, não foisuficiente para a efetivação dos depoimentos: o carinho, a solidariedade e o desejo de colaborar com o sucesso da pesquisa foram primordiais.

Tivemos dois encontros com cada professor, que para nós significaram mais que uma pesquisa, pois foram horas prazerosas, nas quais aprendemos muito com os relatos de experiências, conselhos e suas histórias de vida.

\section{Compreendendo os depoentes}

\section{Professor Amastorzinho Cidreira}

Nosso primeiro contato foi com o professor Amastorzinho Cidreira. Nasceu no dia 13 de maio de 1930, no município de Jequié, em Itagi. Em 1945, cursou o $4^{\circ}$ ano primário. Devido à situação financeira da família, abandonou os estudos, retornando em 1960, quando já estava casado e era pai de três filhos. Tendo como profissão a alfaiataria, a insistência da esposa e a falta de condições financeiras foram as condicionantes que motivaram o seu retorno à escola. O professor Amastorzinho conta:

Em 1957 quando eu cheguei aqui em Jequiéeo, eu era alfaiate, e a profissão estava muito a desejar, eu não conseguia cobrir todas as minhas despesas, com uma receita que não ia sequer a $30 \%$ do que eu precisava, eu via a coisa muito feia. Foi aí que a minha esposa primeira, que faleceu, [...] disse: por quevocê não volta a estudar? Então eu voltei a estudar. Eu voltei a estudar com 30 anos 
de idade. [...] Eu não voltei a estudar simplesmente para ser um professor, eu voltei aos estudos para ter um melhor conhecimento e desempenho da vida, agora é claro que como professor eu tive mais condições de encontrar a minha sobrevivência na sociedade. [...] Eu já tinha o desejo de ser professor. [...] O que eu mais queria era ser uma pessoa que tivesse algo para oferecer a alguém, transmitir o conhecimento (Entrevista com o professor Amastorzinho Cidreira, concedida no dia 18 de novembro de 2013)

Diante dessa fala, percebemos que, para Amastorzinho, além do desejo de exercer essa profissão, mediante a sua situação, ser professor era uma oportunidade social de mudar sua condição de vida e trazer estabilidade financeira para a sua família.

De acordo com Amastorzinho Cidreira, retornando ao $5^{\mathrm{o}}$ ano primário, no Instituto Educacional Régis Pacheco (IERP), já em Jequié, pensou em desistir, pois em um determinado dia, na aula de Matemática, não conseguia entender a explicação do professor, o que o deixou preocupado. Na ocasião, porém, contou com a ajuda de seu primo e de outro colega de classe (considerado pelo próprio Amastorzinho como sendo bom aluno em Matemática); os três começaram a estudara matéria juntos, de maneira bem lenta, possibilitando a sua compreensão.

Assim, cada vez mais, Amastorzinho conta que foi se apaixonando pela Matemática, de tal forma que, ao término do $5^{\circ}$ ano, ele já ministrava aulas particulares para alunos que prestariam a prova de admissão ao ginásio. ${ }^{81}$

Em 1967, concluiu o magistério. Mesmo ainda não atuando oficialmente no ensino de Matemática, em 1969, ele participou, em Salvador, de um curso oferecido pela CADES em nível de licenciatura curta. A respeito desse curso, o Professor Amastorzinho Cidreira relata:

Eu tive um curso de 30 dias úteis de ensino. Depois dos 30 dias tivemos uma prova [...], só que a prova de matemática ficou para o dia de sexta-feira. Nós adventistas reconhecemos o dia de sexta-feira como chamado: dia da preparação, pois no pôr-do-sol a gente recebe o dia de sábado, a gente não recebe o dia de sábado à meia-noite, conforme o calendário romano, mas o calendário bíblico diz que a mudança de dia é ao pôr-do-sol. Neste caso eu comecei a fazer a prova de matemática, quando eu cheguei na $36^{\mathrm{a}}$ questão, que ao todo eram 70, o sol estava declinando, aí eu falei com o professor: Professor, não posso mais continuar com essa prova. Olha, quando eu disse isso,'não posso mais continuar com essa prova', ele já foi me dizendo: Você é adventista? Eu disse: sou sim. Ele disse assim: Eu posso olhar aqui no gabarito as suas questões? Eu disse: pode. Aíele olhou. Das 36, eu tinha acertado 32. [...] Só que depois eu recorri, o direito de fazer outra prova ou então dar continuação àque eu tinha começado, a faculdade não aceitou (Entrevista com o professor Amastorzinho Cidreira, concedida no dia 18 de novembro de 2013).

\footnotetext{
${ }^{81}$ Decreto $n^{0} 19.890$ de 18 de abril de 1931 criou os exames de admissão, provas escritas de Aritmética e Português e provas orais de Geografia, História do Brasil e Ciências Naturais, para avaliar se o aluno estava apto para o ensino ginasial (curso secundário) (AKSENEN, 2014).
} 
Compreendemos que os saberes pessoais dos professores consistem nos saberes produzidos no âmbito familiar, no ambiente de vida, na educação, no sentido lato (TARDIF, 2002). O ser professor é constituído por vários saberes e concepções, dentre elas a religiosa. Amastorzinho não finalizou a prova devido a sua crença religiosa. Vale salientar que essa prova era o Exame de Suficiência ${ }^{82}$ e a aprovação em tal exame propiciava o reconhecimento para o professor ser habilitado para ensinar Matemática.

Então, o professor Amastorzinho Cidreira fez o curso da CADES que objetivava; no entanto, por não haver concluído a prova do Exame de Suficiência, não teve o direito de receber o registro para lecionar, pois para a obtenção do título de licenciatura curta fazia-se necessária a aprovação nessa avaliação.

Mesmo assim, ao retornar para Jequié, devido às relações com pessoas influentes, conseguiu atuar como professor: o prefeito da época o contratou para trabalhar no município de Jequié, no Colégio Municipal Celi de Freitas. Além desse colégio, atuou no magistério de um colégio do município de Ubatã.

Segundo Amastorzinho Cidreira, naquele mesmo ano surgiu o concurso público para lecionar pelo estado, atuando como professor primário. Foi aprovado, sendo chamado para ensinar no IERP, em 1969. Como tinha realizado o curso da Campanha de Aperfeiçoamento e Difusão do Ensino Secundário - CADES, e pelo conhecimento que demonstrava, a Secretaria de Educação permitiu-lhe lecionar no ginásio e, assim, ocupou a cadeira de Matemática no $1^{0}$ ano ginasial. No ano posterior, em 1970 , assumiu as turmas do $2^{\circ}$ ano e $3^{\mathrm{a}}$ ano ginasial; em 1971, a turma do $4^{\circ}$ ano ginasial e, depois que realizou diversos cursos, pôde lecionar no ensino de $2^{\circ}$ grau. De 1972 até 1994 , trabalhou com turmas do $1^{\circ}$ ano do ensino de $2^{\circ}$ grau.

Além do IERP, lecionou em outros colégios estaduais e em um colégio particular, como o Colégio Estadual Professor Magalhães Neto e o Centro de Educação Técnica de Jequié - CETEJE, sempre atuando na área de Matemática.

Em 1975, este professor prestou o primeiro vestibular para Pedagogia, na Universidade Estadual de Santa Cruz, e foi aprovado. Cursou cerca de 4 semestres em Ilhéus e, em seguida, deslocava-se para Salvador, em períodos quinzenais ou mensais, durante 4 anos, com Orientação Escolar, para completar o curso de Pedagogia. No entanto, devido ao curso ser a distância, naquela época a Secretaria não dava o direito de receber o diploma.

Apesar de não ter a licenciatura curta ou a licenciatura plena, em Matemática, o professor Amastorzinho participou de diversos cursos de especialização na área, sendo todos realizados na Universidade Federal da Bahia - UFBA. Aposentou-se no ano de 1998.

${ }^{82}$ Maiores detalhes ver item 2.2

ISSN 2526-2882 


\section{Professora Magnólia Santana de Farias}

Magnólia Santana de Farias fez o curso pedagógico, antigo Magistério, realizado no Instituto Estadual Régis Pacheco - IERP. O curso dava o direito de ser professora primária. Concluiu no ano de 1962 e, em seguida, participou de um curso de Treinamento Básico de professor de Ensino Médio em Matemática, promovido pela CADES, em janeiro de 1963. Esse curso, realizado em Salvador, na Faculdade de Filosofia, foi ministrado pelo Professor Ramakrishna ${ }^{83}$.

Segundo Magnólia, após fazer esse curso, ao retornar para sua cidade, ela se candidatou a uma vaga no Centro de Educação Técnica de Jequié - CETEJE e, em 1964, ensinou Matemática no lugar de um professor que tinha sido seu professor, em uma turma de $5^{\mathrm{a}}$ série.

No período de 22 de julho a8 de agosto de 1970 foi realizado um concurso denominado de Exame de Suficiência para oficializar os professores que ainda não tinham registro, conforme Magnólia Santana de Farias afirma em seu depoimento:

[...] o da habilitação eu tomei em Salvador, porque foi assim: existiamos professores que eram nomeados e existiam os professores que eram contratados. Então abriram um concurso de professor e só poderia fazer o concurso quem tinha registro [...]. Na época, eu não tinha registro, então eu não poderia fazer. A secretaria abriu um concurso para os professores que não tinham registro, para receber o registro. [...] Eu fui para Salvador e me inscrevi. Já tinha uma série de colegas há mais de mês tomando curso de didática, se preparando para esse concurso. Quando eu cheguei, o curso já estava terminando, eu assisti a uma aula, que era como apagar o quadro e como dar aula no quadro e ir dividindo e colocando os assuntos, o que até então a gente não sabia. Eu tomei essa aula, mas a moça disse que quem estava chegando por último, tinha que pagar o curso todo. Eu tinha chegado em um dia e o curso ia terminar no outro. Aí eu falei: Bem, então eu não vou, não vou pagar um curso todo, sendo que eu só assisti aum dia, uma manhã só. Aí não fui de tarde, e vim embora e só voltei para fazer a prova no outro dia. A prova começou às 13 horas e terminou às 19 h3o. [...] Passaram três, aqui em Jequié: eu, a Professora Itamaré e a Professora Grimaldina. [...] Esse concurso que nós fizemos nos deu o certificado que, quando veio o plano de carreira, nos deu o direito de ter licenciatura curta (Entrevista com a professora Magnólia Santana de Farias, concedida no dia 11 de dezembro de 2013).

Observamos que a prova era oferecida pela Universidade Federal da Bahia, mas na preparação para a prova, ocurso de didática não era gratuito, portanto, o professor não tinha incentivo financeiro para a sua formação.

Durante a sua trajetória profissional, atuando na docência do CETEJE, Magnólia trabalhou também no IERP como professora de Matemática e Educação Artística, foi

\footnotetext{
${ }^{83}$ Ramakrishna Bagavam dos Santos foi aluno da primeira turma de Matemática da Faculdade de Filosofia da Bahia; formou-se em 1945 e logo em seguida tornou-se professor assistente dessa mesma instituição (BERTANI, 2012) ISSN 2526-2882 
assistente de pavilhão, coordenadora do Supletivo ${ }^{84}$, coordenadora pedagógica e atuou como Unidade Gestora ${ }^{85}$, além de ter sido vice-diretora do Colégio Estadual Professor Magalhães Neto. Aposentou-se na década de 90.

\section{As memórias do professor Amastorzinho Cidreira e da professora Magnólia} Santana de Farias: Movimento da Matemática Moderna e suas implicações

Assim como em outros lugares do Brasil, o MMM chegou até Jequié, ocasionando um profundo impacto nos professores em relação a esse novo roteiro de conteúdos, o rigor nos fundamentos da Teoria de Conjuntos, no ensino de Matemática e novos métodos de ensino, como afirma Magnólia em seu depoimento: "No início foi um pouco difícil para aceitar, porque era uma coisa completamente diferente do que a gente havia visto, [...] e tudo que é novidade tem um pouco de resistência [...]" (Entrevista com a professora Magnólia Santana de Farias, concedida no dia 16 de dezembro de 2013).

Medidas foram tomadas com a intenção de contribuir para a compreensão desses novos conteúdos em sala de aula, e tentar conscientizar os professores para modificar o ensino. Dessa forma, no interior da Bahia, em especial em Jequié, alguns professores foram atendidos pelos cursos oferecidos pela CADES. "Na atuação da CADES destacou-se a realização de cursos, em período de férias, para professores que não tinham o diploma de curso superior e que após os cursos realizavam os Exames de Suficiência, mediante os quais obtinham o direito ao registro permanente" (BÚRIGO, 1989, p.37).

Segundo a professora Magnólia, a primeira vez que ela participou de um dos cursos promovidos pela CADES foi em 1963, nas dependências da Faculdade de Filosofia da Bahia, em Salvador; o ministrante das aulas foi o professor Ramakrishna. De acordo com ela, nada foi abordado a respeito da Matemática Moderna: os conteúdos escolhidos foram aqueles que os professores do Ensino Secundário tinham mais dificuldade para ensinar, pois o curso era em curto período, duração de 30 dias e não dava tempo de explicar todos os conteúdos, então os professores do Ensino Secundário já levavam aqueles conteúdos que normalmente sentiam dificuldade para lecionar ${ }^{86}$, conteúdos do $1^{0}$ ao $4^{0}$ ano do ginásio.

Dessa forma, notamos que existia uma preocupação partindo da CADES em aperfeiçoar os conhecimentos matemáticos dos professores do curso secundário. De acordo com a professora Magnólia, as ideias do MMM só foram inseridas no cotidiano escolar de

\footnotetext{
${ }^{84}$ Curso destinado às pessoas que estavam fora da idade escolar, realizado no IERP, no noturno. O aluno frequentava aulas durante seis meses e depois fazia uma prova. Se fosse aprovado, adquiria o certificado de conclusão do $1^{\circ}$ grau. Funcionava da mesma forma para o $2^{\circ}$ grau.

85Administrava as verbas que a Secretaria de Educação disponibilizava para o Colégio.

86 Sobre os conteúdos que os professores do curso secundário tinham dificuldade de lecionar, a depoente não se recorda.
} 
Jequié na década de 70, quandosurgiramos cursos de preparação difundindo o Movimento, para que os professores pudessem se adaptar e colocar em prática os novos conteúdos e as metodologias diferenciadas. Em contrapartida, quando o professor Amastorzinho Cidreira voltou a estudar no $5^{\circ}$ ano primário, em 1960, em Jequié, ele relata que:

[...] quando eu comecei a estudar a $5^{\mathrm{a}}$ série no IERP já havia Matemática Moderna, no $5^{\circ}$ ano primário foi que eu não dei em 1960, mas em 1961 entrou Teoria de Conjuntos [...]. Então Teoria de Conjuntos era dadacom muita presteza, muita, até mesmo as operações de adição, subtração, multiplicação e divisão, você tinha que fazer tudo na base da Teoria de Conjuntos. Então você dava intersecção de conjuntos, união de conjuntos e etc. Todas as operações começavam sempre com Teoria de Conjuntos, aí agora sim, você começava a estudar as propriedades dos números, depois entrava nas operações quando você começava a dar as operações fundamentais. (Entrevista com Amastorzinho Cidreira, concedida no dia 18 de novembro de 2013).

Observamos pelas falas dos dois professores que não existe uma memória coletiva da forma como foram implementadas as ideias do MMM em Jequié, pois cada um constituiu uma história individualizada sobre este acontecimento. Talvez pudéssemos justificar essa questão devido à resistência dos professores em aceitarem esses novos conceitos defendidos no MMM.

No início do ano de 1969, o professor Amastorzinho Cidreira dirigiu-se a Salvador para participar do curso promovido pela CADES que, como já foi citado anteriormente, tinha o objetivo de preparar os professores do Ensino Secundário para o Exame de Suficiência, no qual era fornecido o registro permanente. O professor Amastorzinho relata que foram 30 dias intensivos de aulas de Matemática, com conteúdos da $5^{\mathrm{a}}$ à $8^{\mathrm{a}}$ série, sendo que cada semana era trabalhado o conteúdo de uma série: na primeira semana era a $5^{\mathrm{a}}$ série, na segunda semana a $6^{\mathrm{a}}$ série e assim sucessivamente. Segundo sua narrativa, não eram trabalhados todos os conteúdos: o ministrante do curso escolhia um conteúdo, os professores participantes faziam a leitura e as dúvidas eram discutidas.

Em termos de quais conteúdos eram defendidos no MMM, afirma Amastorzinho que, no curso da CADES, “Teoria de Conjuntos era uma das coisas indispensáveis, era exigido de maneira muito criativa, depois operações fundamentais, depois expressões com números inteiros, depois se viam problemas." (Entrevista com o professor Amastorzinho Cidreira, concedida no dia 18 de novembro de 2013). Essa exigência na criatividade demonstra uma preocupação com o método de ensino: não era suficiente introduzir o novo conteúdo no currículo escolar e o professor trabalhar da mesma forma que já vinha fazendo anteriormente com os demais conteúdos, era necessário repensar a metodologia adotada pelos professores para melhor ensinar o assunto. 
Segundo o professor Amastorzinho, no curso da CADES "falavam que metodologia é o caminho mais fácil, mais rápido para o aprendizado, esse era o argumento de todos os professores". Sobre esse mesmo curso, relata o Professor Amastorzinho uma experiência que muito lhe marcou:

A professora no fim do curso da CADES, que durou um mês, disse assim: olha, eu vou sortear um nome para dar uma aula de 55 minutos e nós vamos ter aqui 4 professoras da faculdade que vão avaliar a aula da pessoa. 'Professora, pode me reprovar!', a sala inteira, 38 alunos, 37 menoseu. 'Professora, pode me reprovar, pode me dar zero, pode fazer o que quiser, porque eu não tenho psicologicamente a mínima condição de dar uma aula de matemática mesmo que for só de 55 minutos olhando pra quatro pessoas me fiscalizando, não tenho condição, na minha sala eu sei dar aula, mas aqui não, aqui eu não tenho condição [...]'. Eu disse assim: professora, faça o sorteio do assunto. Ela sorteou e caiu fração. [...] Eu disse: agora, professora, só tem uma coisa: a senhora vai querer o nosso período aqui da manhã? Ele dura 2 horas e 40 minutos. Se eu precisar das 2 horas e 40 minutos, a senhora me dá? Resposta da professora: claro que eu dou, fica à vontade, agora cuidado com a didática. Professor Amastorzinho: Não tenha medo, eu sei trabalhar um pouquinho com a didática [...] Eu comecei a introduzir fração. Então eu comecei assim, eu peguei um tablete de chocolate e disse assim: eu vou quebrar esse tablete de chocolate, pois no ensino do pouco que você ensinar, você precisa, eu preciso, quantos outros, precisam levar em consideração aquilo que se chama metodologia, é tudo em qualquer matéria que você leciona. [...] Quando eu comecei a quebrar o tablete de chocolate em pedaços diferentes, eu disse assim: vocês chamam um pedaço desses de fração? Uma fração do tablete? A maioria disse que sim. Eu disse: olha, a comissão que tá aqui acha que não, pois eles não foram divididos em partes iguais, eles foram divididos em partes desiguais, então não se trata de fração, se trata de um pedacinho do tablete. Mas agora sim, eu peguei outro e dividi em quatro partes bem iguais. Aqui sim, uma quarta parte, mais uma quarta parte e somando as quatro partes forma um tablete inteiro. Depois, tipos de fração, igualdade das frações, equivalência das frações, depois entrei em operações: adição, subtração, multiplicação e divisão. Depois, eu selecionei umas três questões e fiz no quadro cuidadosamente. [...] Finalmente, quando eu terminei os oito modelos de problemas fracionários, eu disse assim: agora, professora, a senhora vai me permitir eu fazer uma crítica a essa apostila que a Faculdade de Filosofia da Bahia elaborou para esse curso, é uma crítica construtiva que tem que ser feita. Umadas professoras da Faculdade perguntou: Uma crítica? [...] Chamaram o coordenador Doutor Rosalvo ${ }^{87}$, falaram da censura que eu fiz, o coordenador disse assim: é vergonhoso um aluno fazer uma observação em plena sala de aula em uma apostila que foi organizada pela Faculdade de Filosofia da Bahia (Entrevista com o professor Amastorzinho Cidreira, concedida no dia 18 de novembro de 2013).

Diante dessa experiência contada pelo professor Amastorzinho, destacamos alguns pontos, os quais chamaram a nossa atenção. O primeiro deles é a preocupação da ministrante com relação à didática. O segundo é a maneira adotada pelo professor, aluno do curso, para abordar o conteúdo, fazendo uso do material alternativo para mostrar o conceito de fração e

87 Rosalvo Otacílio, professor do curso de Didática Especial da Matemática, em 1967, na Faculdade de Filosofia da Bahia. (BERTANI, 2012, p. 64). 
de problemas para mostrar as frações. O terceiro é a censura feita a Amastorzinho pelo coordenador do curso, como se um professor do Ensino Secundário não pudesse discutir o "conhecimento dos professores da Faculdade de Filosofia da Bahia". Destacamos aqui o "valor simbólico" produzido pelos professores da instituição, pois não aceitavam o questionamento em relação ao conhecimento.

Outra forma de simbolizar a importância da Faculdade de Filosofia eram os exames de suficiência, como relata a professora Magnólia que, em 1970, realizou o Exame de Suficiência, que consistia em duas etapas: na primeira o candidato realizava uma avaliação sobre conteúdos de Matemática da $1^{\mathrm{a}}$ à $4^{\mathrm{a}}$ série do ginásio e, se aprovado, faria a segunda etapa, que era uma prova oral na Faculdade de Filosofia. A segunda prova era didática e o candidato seria avaliado em uma aula, tendo como banca três professores da Faculdade de Filosofia.

Apesar de a professora Magnólia não ter notado essa preocupação com novos métodos de ensino anteriormente, percebemos na segunda etapa do Exame de Suficiência uma atenção maior para a forma de transmissão do conteúdo, já que uma das exigências era que a aula fosse realizada "com toda a didática".

Segundo o professor Amastorzinho, os conteúdos que foram defendidos pelo MMM já estavam presentes quando ele estudava no ensino secundário, em 1960. Para ele, as mudanças metodológicas em Jequié só começaram a ocorrer a partir do ano de 1969, quando foi introduzido o método de estudo em equipe:

A partir de 1969 a gente fazia, em uma sala de trinta alunos, a gente dividia em cinco equipes, em cada equipe a gente colocava sempre um aluno mais experiente. Por exemplo, numa sala de trinta alunos você separava cinco alunos que eram bons alunos, tinham um bom aproveitamento, então esses alunos seriam líder da equipe. Isso era orientação da própria Secretaria de Educação, não era um critério estabelecido por professor, era um critério estabelecido pela estrutura e funcionamento da educação de todo o país. Em qualquer colégio que você chegasse, esse método era aceito de bom agrado (Entrevista com o professor Amastorzinho Cidreira, concedida no dia 18 de novembro de 2013).

Esse depoimento nos remete ao argumento usado em um dos trabalhos apresentados no III Congresso Nacional do Ensino da Matemática:

A nova forma de estudo dirigido visa à homogeneização da turma, no que concerne à formação do educando, e esta é a grande razão para formarmos grupos não homogêneos, incentivando o intercâmbio de ideias e a socialização do aluno. Aos mais privilegiados é dada oportunidade de se tornarem úteis e de reafirmarem sua personalidade e, aos que encontram mais dificuldade, a oportunidade de se integrarem nos grupos e na turma (III CONGRESSO NACIONAL DO ENSINO DA MATEMÁTICA, 1959, p. 70). 
A professora Magnólia Santana de Farias declara que a mudança metodológica que ocorreu foi a introdução de estudos em grupos na sala de aula. Segundo ela, essa prática veio não só na Matemática, mas em todas as áreas de conhecimento, pois no período em que foi introduzida a MM em Jequié, ocorreram reformas em outras áreas, fazendo que os professores das demais disciplinas também começassem a trabalhar com formação de equipes para resolução de exercícios. Na Matemática, entretanto, isso foi trabalhado por pouco tempo, pois não houve resultados satisfatórios, e o método foi suspenso. Foi neste momento, para a entrevistada, que começou a haver a inserção de novos conteúdos, já que se recorda claramente de Teoria de Conjuntos. A depoente considera que tenha lembrança apenas da Teoria de Conjuntos devido ao tempo que trabalhou em sala de aula, voltado para turmas de $6^{\mathrm{a}}$ e $7^{\mathrm{a}}$ série.

A partir de 1969, diversos cursos de preparação para o Movimento da Matemática Moderna foram promovidos pela Secretaria da Educação, realizados em Salvador, alguns no Colégio Estadual de Salvador e outros na Escola Técnica Federal da Bahia. Era determinado que todos os professores participassem;no entanto, quando algum justificava que não poderia ir, os demais presentes tinham que explicar o que foi abordado no curso para os que não foram, "era sempre determinado um tempo para a preparação de seminários” (Entrevista com o professor Amastorzinho Cidreira, concedida no dia 18 de novembro de 2013), quando retornassem ao colégio em Jequié. Com isso percebemos o grande interesse do estado em difundir as questões tratadas no MMM, tanto em relação aos novos conceitos quanto aos novos métodos de ensino.

Um dos cursos que o professor Amastorzinho realça é o de Fundamentação Metodológica do Ensino de Matemática do $1^{\circ}$ e $2^{\circ}$ grau, realizado em Salvador, que tinha como ministrante a professora Maria Aparecida ${ }^{88}$. Ela orientava os professores do Ensino Secundário sobre a maneira de abordar o conteúdo e assim, durante o período em que estavam em suas salas de aula, nos respectivos colégios, lecionando, trabalhavam o conteúdo com a metodologia indicada. Quando terminava aquela etapa, que durava cerca de um semestre, retornavam e aprendiam novos conteúdos e metodologias.

O professor Amastorzinho lembra que participou de diversos cursos que abordavam sobre os conteúdos que seriam inseridos no currículo e as mudanças nas práticas de ensino. Em contrapartida, a professora Magnólia em seu depoimento diz que só participou de um curso que abordava esses temas. Para ela, as mudanças que ocorreram em termos de conteúdo foram a inserção da Teoria de Conjuntos e asmudanças metodológicas como trabalho em equipe, que antes não se falava em agrupamento em sala de aula, formavam-se grupos para estudar em casa.

${ }^{88}$ Não conseguimos identificar o sobrenome dessa professora. ISSN 2526-2882

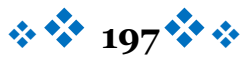


Esse curso sobre o quala professora Magnólia nos relata, e doqual participou, foi realizado em Jequié no IERP local onde lecionava, promovido pela Secretaria de Educação. O nome do professor ministrante do curso era Alberto $^{89}$ e vieram professores do curso secundário de todo o interior da Bahia.

$\mathrm{Na}$ entrevista, o professor Amastorzinho enfatizou a mudança na figura do professor que antes se comportava como o único detentor do saber e não se preocupava com o aprendizado do aluno, a preocupação era "em cumprir o conteúdo". Segundo ele, tanto no curso da CADES quanto nos demais cursos de que participou, "quase que a oração geral era essa: você não se escravize a vomitar conhecimento. Pelo contrário você se iguale ao seu aluno, entre no nível do seu aluno" (Entrevista com o professor Amastorzinho Cidreira, concedida no dia 18 de novembro de 2013). Ele ainda nos relatou que:

Era permitido ao professor desenvolver, à medida que ele apresentava a matéria na aula, ele fazia um teste de avaliação, chamada avaliação formativa. É aquela que você está experimentando o aluno, àmedida que você vaidando aula. Então, quando você notava que o aluno estavatendo muita dificuldade, você flexibilizava mais o conteúdo, você não deixava de dar Geometria, mas dentro de Geometria você dava um conteúdo um pouco mais suave. Pois a filosofia naquele tempo era assim: melhor o aluno ter segurança plena em 50\% do conteúdo, do que o professor alinhavar porque tem conhecimento de dar aquele conteúdo pesado ao aluno e o aluno não absorver. Então é muito mais proveitoso você dar 50\% do conteúdo. Eu não estou dizendo aqui que estamos fugindo do conteúdo, é o mesmo conteúdo só que você flexibilizou um pouco [...] (Entrevista com o professor Amastorzinho Cidreira, concedida no dia 18 de novembro de 2013).

O depoimento acima nos mostra a importância que passaram a dar para a aprendizagem. Quando o entrevistado fala dessa "avaliação formativa", demonstra que era uma forma de o professor avaliar individualmente o nível de aprendizagem de cada aluno, levando em consideração que não basta o professor querer "transmitir” o máximo de conteúdos e ir aprofundando sempre, se o aluno não conseguir aprender o conteúdo.

\section{Considerações finais}

As narrativas dos dois professores trouxeram indícios de que as propostas de mudanças curriculares e metodológicas ocasionaram, no período estudado, um impacto nos professores do curso secundário de Jequié, pois tanto os conteúdos que seriam inseridos no currículo, quanto os novos métodos de ensino influenciariam diretamente na prática de ensino.

No entanto, para subsidiar esses professores e prepará-los para esse novo rumo que o ensino da Matemática estava tomando, cursos foram oferecidos para que os professores

${ }^{89} \mathrm{~A}$ professora Magnólia não se recorda do sobrenome desse professor. ISSN 2526-2882 
pudessem se apropriar das novas recomendações para o ensino. Assim, esses cursos eram disponibilizados por meio da CADES, que "teve fundamental importância na história da educação no Brasil, particularmente na sua atuação na formação do professor de Matemática no ensino secundário em várias regiões do país, por meio de seus cursos” (BRAGA, 2012, p.19).

Dias (2011) afirma que esses cursos de formação de professores, promovidos pela CADES, passaram a atender a numerosa demanda de professores leigos, atuantes do Ensino Secundário de todo o interior da Bahia. Do município de Jequié, professores do curso secundário se dirigiram a Salvador para se aperfeiçoar tanto em relação à renovada Matemática, quanto aos novos métodos de ensino.

Foi possível verificar, nessa pesquisa, que a Secretaria de Educação solicitava à direção da escola que orientasse os professores do ensino secundário de Jequié a participarem dos cursos oferecidos. Entretanto, mesmo participando, não foram todos que aderiram às novas propostas de metodologia. Conforme os relatos da professora Magnólia, a falta de recursos que possibilitassem mudanças na prática de ensino foi responsável pelo desinteresse de alguns professores em mudar. $O$ único materialde que dispunham era o livro didático, que chegava às escolas e os professores individualmente estudavam e tentavam passar para o aluno da melhor maneira possível para que houvesse compreensão.

Por outro lado, o professor Amastorzinho relata uma concepção diferente, pois, mesmo com as dificuldades apresentadas pela falta de recurso, buscava colocar em prática o que lhe era ensinado nos cursos. O entrevistado se preocupava com a forma como o aluno aprende, e buscava trazer algo da realidade do aluno para explicar o conteúdo que estivesse abordando, além de propor a formação de grupos de estudo na sala de aula.

Assim, durante a análise das narrativas podemos destacar que cada professor constituiu uma história particular sobre esse período.

\section{Referências}

AKSENEN, M. E. B. M. Desvelando os Exames de Admissão ao ginásio na educação Paranaense. Revista HISTEDBR On-line. Campinas, n.58, p.230-243, set. 2014.

BERTANI, J. A. Formação de Professores de Matemática: um estudo histórico comparativo entre Bahia e Portugal (1945-1968). 2012. 217p. Tese (Doutorado em Ensino, Filosofia e História das Ciências). Universidade Federal da Bahia; Universidade Estadual de Feira de Santana, Salvador, BA, 2012.

BRAGA, M. N. S. O Programa de Treinamento e Aperfeiçoamento de Professores de Ciências Experimentais e Matemática - PROTAP (1969-1974): Sua contribuição para a Modernização do Ensino de Matemática. 2012. 94p. Dissertação 
(Mestrado em Ensino, Filosofia e História das Ciências). Universidade Federal da Bahia; Universidade Estadual de Feira de Santana, Salvador, BA, 2012.

BÚRIGO, E. Z. Movimento da Matemática Moderna no Brasil: Estudo da Ação e do pensamento de Educadores Matemáticos nos anos 60. 1989. 286p. Dissertação (Mestre em Educação). Universidade Federal do Rio Grande do Sul, Porto Alegre, RS, 1989.

CIDREIRA, A. Entrevista concedida a Naiane Novaes Nogueira, Jequié, o3 e 18 de novembro de 2013.

CHARTIER, R. Cultura escrita, literatura e história. Conversas de Roger Chartier com Anaya, Rosique, Goldin e Saborit. Porto Alegre, RS: Artmed, 2001.

CONGRESSO NACIONAL DE ENSINO DA MATEMÁTICA NO CURSO SECUNDÁRIO.

Salvador: Universidade da Bahia, 1955.

CONGRESSO NACIONAL DE ENSINO DA MATEMÁTICA. Porto Alegre, 1957.

DIAS, A. L. M. et al. Uma História da Educação Matemática na Bahia. In: XXVI Simpósio Nacional de História. São Paulo: ANPUH, 2011.

FARIAS. M. S. Entrevista concebida a Naiane Nogueira Borges Souza. Jequié, 5 de novembro e 11 de dezembro de 2013.

FREIRE, I. A. A.; DIAS, A. L. M. Seção Científica de Matemática do CECIBA: propostas e atividades para renovação do ensino secundário de matemática (1965-1969). Bolema, Rio Claro, v.23, n.35B, p.363-386, abr. 2010.

GARNICA, A. V. M. A História Oral como recurso para a pesquisa em Educação Matemática: um estudo do caso brasileiro. Porto. V CIBEM, 2005.

LANDO, J. C. Práticas, Inovações, Experimentações e Competências Pedagógicas das Professoras de Matemática no Colégio de Aplicação da Universidade da Bahiav (1949-1976). 2012. 307p. Tese (Doutorado em Ensino, Filosofia e História das Ciências). Universidade Federal da Bahia; Universidade Estadual de Feira de Santana, Salvador, BA, 2012.

RIOS, D. F. Memórias de Ex-alunos do Colégio de Aplicação da Bahia: contribuições para a História da Educação Matemática. Bolema, v.30, n.56, Rio Claro, set/dez., 2016.

SANTOS, J. C. T. Demonstrações Matemáticas na Coleção de livros didáticos “Matemática Moderna” publicada na década de 1960, na Bahia. 2013.81p. Monografia (Graduação em Licenciatura em Matemática com Enfoque em Informática). Universidade Estadual do Sudoeste da Bahia, Jequié, BA, 2012.

SILVA, M. C. L.; CAMARGO, K. C. Martha Dantas: O ensino da Geometria na Bahia. Revista Diálogo Educacional, Curitiba, v.8, n.25, p.701-714, 2008. 
SOARES, F. Os congressos de ensino da Matemática no Brasil nas décadas de 1950 e 1960 e as discussões sobre a Matemática Moderna. Diálogos Temáticos 5: História da Educação Matemática. $1^{\mathrm{o}}$ Seminário Paulista de história e educação Matemática: possibilidades de diálogos. IME (USP), 2005.

TARDIF, M. Saberes docentes e formação profissional. 4. ed. Rio de Janeiro: Vozes, 2002.

\section{Biografia Resumida}

Naiane Nogueira Borges Souza: Professora da Escola Monteiro Lobato. Graduada no curso de Licenciatura em Matemática com enfoque em informática. Atua na Educação Básica.

Link Lattes: http://Link Lattes.cnpq.br/4972518154392330

e-mail: n_n_nai@hotmail.com

Januária Araújo Bertani: Professora da Universidade Estadual do Sudoeste da Bahia (UESB). Doutora em Ensino, Filosofia e História das Ciências pelo Universidade Federal da Bahia/Universidade Estadual de Feira de Santana (UBBA/UEFS). Atua no Curso de Licenciatura em Matemática com Enfoque em Informática.

Link Lattes: http://Link Lattes.cnpq.br/4214942080772271

e-mail: bertani.januaria@gmail.com 